\title{
Erratum to: Entangling Relation of Micro RNA-let7, miRNA-200 and miRNA-125 with Various Cancers
}

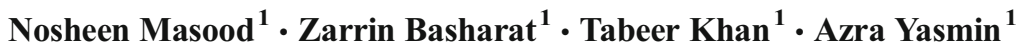

Published online: 29 April 2017

(C) Arányi Lajos Foundation 2017

Erratum to: Pathol. Oncol. Res.

DOI 10.1007/s12253-016-0184-0

The original version of this article unfortunately contained an error in the author group section.

The author group should have been Nosheen Masood, Zarrin Basharat, Tabeer Khan and Azra Yasmin instead of Nosheen Masood \& Azra Yasmin.

The corrected author group is shown above.

The online version of the original article can be found at http://dx.doi.org/ 10.1007/s12253-016-0184-0

Nosheen Masood

nosheenmasood@hotmail.com

Zarrin Basharat

zarrin.iiui@gmail.com

Tabeer Khan

tabeerkh@gmail.com

Azra Yasmin

azrayasmin@fjwu.edu.pk; azradr@yahoo.com

1 Fatima Jinnah Women University, The Mall, Rawalpindi, Pakistan 